\title{
Monoamine Oxidase Inhibition Dramatically Increases the Motivation to Self-Administer Nicotine in Rats
}

\author{
Karine Guillem, ${ }^{1}$ Caroline Vouillac, ${ }^{1}$ Marc R. Azar, ${ }^{2}$ Loren H. Parsons, ${ }^{2}$ George F. Koob, ${ }^{2}$ Martine Cador, ${ }^{1}$ and \\ Luis Stinus ${ }^{1}$ \\ ${ }^{1}$ Laboratoire de Neuropsychobiologie des Désadaptations, Unité Mixte de Recherche 5541, Centre National de la Recherche Scientifique, Université de \\ Bordeaux 2, 33076 Bordeaux Cedex, France, and ²Department of Neuropharmacology, The Scripps Research Institute, La Jolla, California 92037
}

\begin{abstract}
Nicotine is the major neuroactive compound of tobacco, which has, by itself, weak reinforcing properties. It is known that levels of the enzymes monoamine oxidase A (MAO-A) and MAO-B are reduced in the platelets and brains of smokers and that substances, other than nicotine, present in tobacco smoke have MAO-inhibitory activities. Here, we report that inhibition of MAO dramatically and specifically increases the motivation to self-administer nicotine in rats. These effects were more prominent in rats selected for high responsiveness to novelty than in rats with low responsiveness to novelty. The results suggest that the inhibition of MAO activity by compounds present in tobacco smoke may combine with nicotine to produce the intense reinforcing properties of cigarette smoking that lead to addiction.
\end{abstract}

Key words: nicotine self-administration; tranylcypromine; phenelzine; high and low responders; fixed ratio; progressive ratio

\section{Introduction}

Tobacco addiction remains the most prevalent addiction in the world today, with significant associated pathology and costs to society. Nicotine is the neuroactive compound that is considered to be most responsible for the psychoactive properties of tobacco and the development and maintenance of tobacco addiction (Jaffe and Kanzler, 1979; Stolerman and Jarvis, 1995; Pontieri et al., 1996).

However, nicotine is not the only compound of tobacco. There are $>4000$ chemical constituents in tobacco smoke, some of which have psychopharmacological effects and thus may contribute to tobacco dependence. Preclinical and clinical studies have demonstrated that current smokers have lower brain monoamine oxidase A (MAO-A) and MAO-B activity, which normalizes during prolonged abstinence (Berlin et al., 1995; Fowler et al., 1996a,b; Berlin and Anthenelli, 2001). Furthermore, it has been shown that an as yet unidentified component of tobacco smoke (not nicotine) inhibits both MAO-A and MAO-B (Poindexter and Carpenter, 1962; Fowler et al.; 1996a; Rommelspacher et al., 2002), suggesting that non-nicotinic receptor mechanisms may be involved in the psychoactive properties of tobacco.

In addition, it has been shown in several species that nicotine has relatively weak reinforcing properties compared with other addictive drugs. Such a weak reinforcing property cannot explain by itself the intense addictive properties of tobacco smoking, the

Received March 3, 2005; revised Aug. 3, 2005; accepted Aug. 4, 2005.

K.G. was supported by a grant from the Association pour la Recherche sur les Nicotianées, Fleury les Aubrais, France. G.F.K. was supported by Tobacco-Related Disease Research Program Grant 12RT-0099 from the state of California. We thank Mike Arends for his assistance with the preparation of this manuscript.

Correspondence should be addressed to Dr. Luis Stinus, Laboratoire de Neuropsychobiologie des Désadaptations, Unité Mixte de Recherche 5541, Centre National de la Recherche Scientifique, Université de Bordeaux 2, Boîte Postale 31, 146 rue Léo Saignat, 33076 Bordeaux Cedex, France. E-mail: luis.stinus@Inpb.u-bordeaux2.fr.

D0I:10.1523/JNEUROSCI.2139-05.2005

Copyright $\odot 2005$ Society for Neuroscience $\quad$ 0270-6474/05/258593-08\$15.00/0 difficulty most smokers experience in attempting to quit, and the high relapse rates after quitting (Goldberg et al., 1981; Corrigall and Coen, 1989; Donny et al., 1995; Rose and Corrigall, 1997). There is also considerable individual variability in abuse and frequency of consumption associated with smoking as with other drugs of abuse. In animal models, as in humans, not all rats readily self-administer nicotine, and some aspects of the propensity of the animals to self-administer drugs can be predicted by their locomotor response to novelty (Piazza et al., 1989; Suto et al., 2001).

Because MAO is involved in the degradation of physiologically active monoamines, including some of those released by nicotine, it can be hypothesized that decreased MAO activity induced by MAO inhibitors (MAOIs) contained in tobacco smoke may be involved in the reinforcing properties of tobacco. Thus, the aim of the present study was to assess the possibility of a synergistic interaction between nicotine and two MAOIs by determining the effects of chronic MAOI treatments during intravenous nicotine self-administration (SA) in a subpopulation of rats selected on the basis of their spontaneous level of locomotor activity in response to novelty exposure.

\section{Materials and Methods}

Animals

Male Sprague Dawley rats (352; from Iffa Credo, Lyon, France), weighing $175-200 \mathrm{~g}$ at the beginning of the experiment, were used. They were housed in groups of four and maintained in rooms at $20-22^{\circ} \mathrm{C}$ with a reverse light/dark cycle (lights off from 9:00 A.M. to 9:00 P.M.). Food access was restricted to $20 \mathrm{~g} / \mathrm{d}$ delivered after the self-administration session.

\section{Drugs}

(-)Nicotine hydrogen tartrate, tranylcypromine hydrochloride (TCP), and phenelzine sulfate (PLZ) were purchased from Sigma (St. Louis, $\mathrm{MO})$ and were dissolved in isotonic $\mathrm{NaCl}(0.9 \% \mathrm{w} / \mathrm{w}$ saline in water $)$. MAOIs were administered intraperitoneally $(1.0 \mathrm{ml} / \mathrm{kg}$ body weight $)$ at 
the following doses, expressed as free base: TCP [1.5 (TCP-1.5), 3, or 4.5 $\left.\mathrm{mg} \cdot \mathrm{kg}^{-1} \cdot \mathrm{d}^{-1}\right]$ and PLZ $\left[0.5,1,2(\mathrm{PLZ}-2)\right.$, or $\left.4 \mathrm{mg} \cdot \mathrm{kg}^{-1} \cdot \mathrm{d}^{-1}\right]$. Control rats received vehicle. Doses of MAOIs were chosen based on previously determined dose-response relationships on locomotor activity for which no psychostimulant effects had been detected from the MAOIs alone. The doses of MAOIs selected for the nicotine SA and foodmaintained responding experiments were $1 \mathrm{U}$ dose below the psychostimulant dose (TCP, $1.5 \mathrm{mg} / \mathrm{kg}$; PLZ, $2 \mathrm{mg} / \mathrm{kg}$ ). Treatments with MAOIs began on the first day of each experiment and occurred $1 \mathrm{~h}$ before each daily session.

\section{Locomotor activity recording}

Apparatus. Locomotor activity was measured in activity cages $(41 \times 26 \times$ $28 \mathrm{~cm}$ ) with wire mesh floors and $10 \mathrm{~mm}$ Plexiglas side walls (Imetronic, Pessac, France). Two infrared photoelectric cells were located $14 \mathrm{~cm}$ apart and $3 \mathrm{~cm}$ above the floor. The activity cages were kept in a dimly lit room with white noise continuously present. Total motor activity (total number of beam interruptions) was recorded every $10 \mathrm{~min}$ for locomotor response to novelty and for acute effects of MAOIs or every $24 \mathrm{~h}$ for chronic MAOI treatments.

Locomotor activity after acute MAOI treatments. To have a low activity baseline, activity recordings were performed during the light phase. All rats were habituated previously to experimental cages. Three hours after lights on, rats were habituated to activity cages for $2 \mathrm{~h}$, subsequently injected with vehicle $(1 \mathrm{ml} / \mathrm{kg})$. Activity was recorded for $2 \mathrm{~h}$, and the rats were then injected with vehicle $(n=29)$, PLZ $(0.5,1,2$, or $4 \mathrm{mg} / \mathrm{kg} ; n=$ $6,6,9$, and 6 , respectively), or TCP $(1.5,3$, or $4.5 \mathrm{mg} / \mathrm{kg} ; n=8$ for each group), and locomotor activity was recorded for $3 \mathrm{~h}$.

Locomotor activity after chronic MAOI treatments. The experiment lasted for $25 \mathrm{~d}$. Doses of PLZ and TCP were chosen according to their inability to modify locomotor activity after acute injection (INJ). Twenty-eight animals completed the experiment (vehicle, $n=15$; PLZ-2, $n=8$; TCP-1.5, $n=5$ ). Animals were permanently housed in eight individual cages, allowing continuous recording of locomotor activity. Temperature, light/dark cycle, and food and water availability were identical to the animal colony housing conditions. After a $5 \mathrm{~d}$ habituation period, baseline locomotor activity was established (mean of the last $3 \mathrm{~d}$ ). During the subsequent $8 \mathrm{~d}$, once per day, rats received vehicle, PLZ-2, or TCP-1.5 (chronic MAOI phase). Then, treatment was interrupted, and locomotor activity was recorded for $9 \mathrm{~d}$ (withdrawal phase).

Effects of chronic MAOI treatments on nicotine-induced locomotion and behavioral sensitization. The experiment lasted for $6 \mathrm{~d}$. Each day, rats were pretreated with vehicle, TCP-1.5, or PLZ-2. One hour later, they were injected with vehicle or several doses of nicotine $[0 \mathrm{mg} / \mathrm{kg}$ (Nic-0), 0.2 $\mathrm{mg} / \mathrm{kg}$ (Nic-0.2), and $0.4 \mathrm{mg} / \mathrm{kg}$ (Nic-0.4), s.c[, and locomotor activity was immediately recorded for $20 \mathrm{~min}$. The following groups were used: vehicle-Nic-0, TCP-1.5-Nic-0, PLZ-2-Nic-0, vehicle-Nic-0.2, TCP1.5-Nic-0.2, PLZ-2-Nic-0.2, vehicle-Nic-0.4, TCP-1.5-Nic-0.4, and PLZ-2-Nic-0.4 ( $n=10$ for each group).

\section{Locomotor response to novelty}

All animals were exposed to activity cages $(41 \times 26 \times 28 \mathrm{~cm})$ in which locomotor activity was monitored for $2 \mathrm{~h}$ (light phase). Each experimental cage was equipped with two parallel horizontal infrared beams positioned $2 \mathrm{~cm}$ above the floor and spaced $13.5 \mathrm{~cm}$ apart along the longitudinal axis. Photocell beam interruptions were monitored and recorded via a microcomputer system. The activity cages were kept in a dimly lit room with white noise continuously present. According to the total activity scores, rats were allocated into one of two groups: rats with locomotor activity scores in the upper third were designated high responders (HRs), and rats with locomotor scores in the lower third were designated low responders (LRs). Rats in the middle third were discarded.

\section{Blood sampling, nicotine, and cotinine assays}

The purpose of this study was to evaluate the effects of MAOI treatments on nicotine clearance, and its accumulation after repeated intravenous injections of nicotine ( $30 \mu \mathrm{g} / \mathrm{kg}$ per injection, free base) at $12 \mathrm{~min}$ intervals to mimic nicotine $S A$. Rats were pretreated for $5 \mathrm{~d}$ with vehicle $(n=$ 4), TCP $\left(1.5 \mathrm{mg} \cdot \mathrm{kg}^{-1} \cdot \mathrm{d}^{-1}\right.$, i.p.; $\left.n=4\right)$, or PLZ $\left(2 \mathrm{mg} \cdot \mathrm{kg}^{-1} \cdot \mathrm{d}^{-1}\right.$, i.p.; $n=5)$. On the fifth day, catheters were implanted into the external jugular vein and femoral vein for nicotine injections and blood sampling, respectively. Rats then received MAOI treatment, followed 60 min later by intravenous injections of nicotine at $0 \mathrm{~min}$ and collection of blood samples $(200 \mu \mathrm{l})$ at $3,7,11$, and $15 \mathrm{~min}$. The first nicotine injection was followed by repeated nicotine injections at $20,32,44$, and $56 \mathrm{~min}$ and blood sampling at $31,43,55$, and $67 \mathrm{~min}$.

Nicotine and cotinine were extracted from $100 \mu \mathrm{l}$ aliquots of plasma by adding $10 \mu \mathrm{l}$ of a $1 \mu \mathrm{M}$ concentration of 2-phenylimidazole (as an internal standard) and $20 \mu \mathrm{l}$ of $20 \% \mathrm{NaOH}$ (vortexed), followed by 400 $\mu \mathrm{l}$ of dichloromethane (DCM). After mixing and centrifugation $(1500 \times$ $g$ for $10 \mathrm{~min}$ ), the aqueous layer was discarded, and $10 \mu \mathrm{l}$ of $6 \mathrm{M} \mathrm{HCl}$ was added to the DCM layer. After mixing and centrifugation as above, the DCM layer was transferred to a new microcentrifuge tube, evaporated under a gentle stream of nitrogen, and then stored at $-70^{\circ} \mathrm{C}$ until analysis. Nicotine and cotinine levels were determined using liquid chromatography (LC)-mass spectrometry (MS). The lyophilized samples were reconstituted with $25 \mu \mathrm{l}$ of LC mobile phase containing 0.25 pmol of ethylnorcotinine (MS internal standard) and were separated isocratically by hydrophilic interaction chromatography $(1 \times 150$ mm polyhydroxyethyl-A column; PolyLC, Columbia, MD). Nicotine, cotinine, and the internal standards were detected in their protonated form and quantified using selected ion monitoring at the following mass-to-charge $(\mathrm{m} / \mathrm{z})$ ratios: nicotine $(\mathrm{m} / \mathrm{z}, 163: 1)$; cotinine $(\mathrm{m} / \mathrm{z}$, 177:1); 2-phenylimidazole (m/z, 145:2); and ethylnorcotinine $(\mathrm{m} / \mathrm{z}$, 191:2).

\section{Nicotine self-administration}

Animals were deeply anesthetized with chloral hydrate $(350 \mathrm{mg} / \mathrm{kg}$, i.p.; JT Baker, Deventer, The Netherlands) and an indwelling catheter (SILASTIC tubing; 0.012 inch inner diameter, 0.025 inch outer diameter; Dow Corning, Midland, MI) was surgically implanted into the external jugular vein. The catheter was secured to the vein with surgical silk sutures and passed subcutaneously to the top of the back, where it exited into a connector (modified 22 gauge cannula). After surgery, animals were flushed daily with $0.2 \mathrm{ml}$ of an ampicillin solution $(0.1 \mathrm{~g} / \mathrm{ml} \mathrm{To-}$ tapen; ConvaTec, Paris, France) containing heparin $(300 \mathrm{IU} / \mathrm{ml})$ to maintain patency. Each experimental chamber $(30 \times 40 \times 37 \mathrm{~cm}$; Imetronic) was equipped with two nose-poke operanda. During drug SA sessions, animals' catheters were connected by spring-covered Tygon tubing through a fluid swivel to a $10 \mathrm{ml}$ syringe pump (Razel; Fisher Bioblock Scientific, Illirch, France) located outside the chamber. Pokes in one hole, defined as the active hole, delivered intravenous nicotine infusions ( $30 \mu \mathrm{g} / \mathrm{kg}$ per infusion, free base) in a volume of $100 \mu \mathrm{l}$ over $3 \mathrm{~s}$. Pokes in the other hole, defined as the inactive hole, had no scheduled consequence. Each infusion was paired with a $3 \mathrm{~s}$ cue light located above the active hole and was followed by a $20 \mathrm{~s}$ time out period, during which responding was recorded but not reinforced.

\section{Food-maintained responding}

Four operant chambers were used (Campden Instruments, Loughborough, UK), constructed of aluminum with grid floors. Each chamber was equipped with a food-pellet dispenser, which delivered food pellets into the food tray to which the rat gained access by pushing a panel. There were two levers placed on each side of the food tray, and three panel lights were placed above the levers and tray. After initial shaping to lever press and panel push, rats were exposed to a progressively augmented fixedratio (FR) schedule of reinforcement, until FR5 schedule was attained, with sessions lasting for $30 \mathrm{~min}$. Responding on one lever, defined as the active lever, delivered a single $45 \mathrm{mg}$ food pellet (Research Diets, New Brunswick, NJ). Responding on the other lever, defined as the inactive lever, was also recorded, although it had no scheduled consequence. Each delivery of food pellet was paired with a $3 \mathrm{~s}$ tray-light presentation above the active lever, in the presence of the house light. Food access, other than that earned during the session, was restricted to $20 \mathrm{~g} / \mathrm{d}$ delivered after the session.

\section{Experimental procedures}

Experiment 1: effects of MAOI treatments on nicotine SA and foodmaintained responding on a fixed-ratio schedule of reinforcement. Experi- 
mental sessions started at the beginning of the dark cycle on day 6 of recovery from surgery. Animals ( $\mathrm{LR}, n=27 ; \mathrm{HR}, n=23$ ) were allowed to acquire nicotine SA on FR schedules of reinforcement (days 1-10, FR1; days 11-13, FR2; days 14-23, FR5) in daily $2 \mathrm{~h}$ sessions, at the unit dose of $30 \mu \mathrm{g} / \mathrm{kg}$ nicotine per infusion (free base). An additional group (LR, $n=15$; HR, $n=16$ ) of rats was trained to lever-press for food, as described for nicotine SA. This group received MAOI treatments in the same way as the rats responding for nicotine.

Experiment 2: effects of MAOI treatments on nicotine SA and foodmaintained responding on a progressive-ratio schedule of reinforcement. After establishing stable levels of nicotine SA and food-maintained responding, animals were switched to a progressive-ratio (PR) schedule of reinforcement, under which the number of nose pokes required to obtain each successive infusion ( $30 \mu \mathrm{g} / \mathrm{kg}$ nicotine per infusion) was increased according to the following sequence: $1,3,6,10,15,20,25,32,40$, 50, etc. (Depoortere et al., 1993). In nicotine SA, PR sessions lasted for a maximum of $10 \mathrm{~h}$ or until $1 \mathrm{~h}$ elapsed without a drug infusion. In foodmaintained responding, PR sessions lasted for a maximum of $1 \mathrm{~h}$ or until 15 min elapsed without a food delivery. In each experiment, the last ratio attained (breaking point) was recorded. All of the rats completed the PR session before $60 \mathrm{~min}$.

Experiment 3: effects of MAOI treatments on nicotine dose-response function. Animals (LR, $n=27$; HR, $n=25$ ) were trained to selfadminister nicotine in an identical manner to experiment 1 ( 23 sessions). After stable nicotine SA (training dose, $30 \mu \mathrm{g} / \mathrm{kg}$ nicotine per infusion) was established on the FR5 schedule (10 sessions), the effects of changing the unit dose were examined under FR5 schedule. The nicotine doses ( 3 , $7.5,15,30,45,60$, and $80 \mu \mathrm{g} / \mathrm{kg}$ per infusion, free base) were presented according to a within-subjects Latin square design. Each dose was maintained for at least $3 \mathrm{~d}$ and until responding was stable. Between doses, rats were trained again for $3 \mathrm{~d}$ with the training dose ( $30 \mu \mathrm{g} / \mathrm{kg}$ per infusion).

\section{Data analyses}

Analyses of nicotine SA were performed using ANOVA. For the FR study, only the last $3 \mathrm{~d}$ were analyzed because they best characterized stable responding at a particular phase and were less susceptible to the transitional instability produced by changing the FR schedule. For responding, treatment (vehicle, TCP, and PLZ) and novelty (HR-LR) were betweensubjects factors, and hole (active-inactive) as a within-subjects factor. For analyses of nicotine infusions, treatment and novelty were betweensubjects factors. For the PR study, treatment and novelty were betweensubjects factors for the final ratio attained. In the dose-response experiment, values for response rates and intake on the last day at the given dose were used to calculate dose-effect curves. Data were subjected to a twoway ANOVA, with treatment and novelty as between-subjects factors, and dose (seven levels) as a within-subject factor. Whenever main factor effects were found, post hoc comparisons were performed using the Newman-Keuls test. $p>0.05$ was considered as not statistically significant (NS).

\section{Results}

\section{Locomotor activity after acute MAOI treatments}

Locomotor activity recorded both during the habituation phase and after vehicle injection were identical for all groups $\left(F_{(7,72)}=\right.$ 0.417 , NS; $F_{(7,72)}=0.45$, NS; respectively). After MAOI treatments (Fig. 1), ANOVA indicated group $\left(F_{(7,72)}=5.45 ; p<\right.$ $0.001)$ and time main effects $\left(F_{(2,144)}=135 ; p<0.001\right)$, as well as a group by time interaction $\left(F_{(14,144)}=7.4 ; p<0.001\right)$. When compared with the vehicle group, only TCP induced significant locomotor hyperactivity at the two higher doses, $3 \mathrm{mg} / \mathrm{kg}$ $\left(F_{(1,35)}=9.7 ; p<0.01\right)$ and $4.5 \mathrm{mg} / \mathrm{kg}\left(F_{(1,35)}=24 ; p<0.001\right)$.

\section{Locomotor activity after chronic MAOI treatments}

Locomotor activity baseline was identical for all groups $\left(F_{(2,25)}=\right.$ $0.8, \mathrm{NS})$. When compared with vehicle-treated rats, PLZ-2 and TCP-1.5 animals displayed identical locomotor activity, both during MAOI treatment $\left(8 \mathrm{~d}, F_{(2,25)}=0.75, \mathrm{NS}\right)$ as well as during the withdrawal phase $\left(F_{(2,25)}=0.45, \mathrm{NS}\right)$.

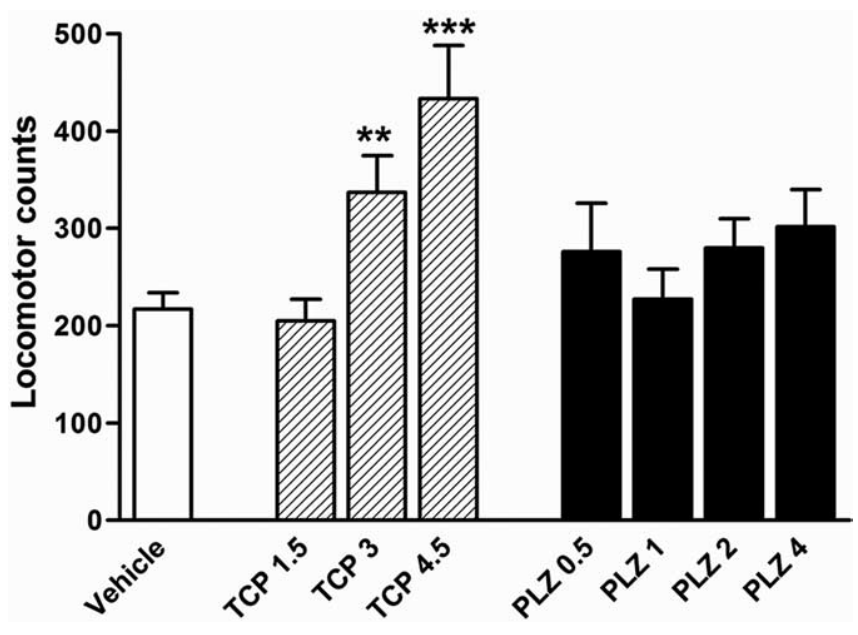

Figure 1. Dose-response effects of acute MAOI treatments on spontaneous locomotor activity (white, hatched, and black bars show vehicle, TCP, and PLZ pretreatment, respectively). Locomotor activity (mean photocell interruptions \pm SEM) was recorded for $3 \mathrm{~h} .{ }^{* *} p<0.01$ and ${ }^{* * *} p<0.001$, significant difference when compared with vehicle-injected rats.

\section{Effects of chronic MAOI treatments on nicotine-induced locomotion and behavioral sensitization}

The three-way ANOVA revealed a significant effect of nicotine $\left(F_{(2,81)}=64.7 ; p<0.001\right)$ but no effect of treatment $\left(F_{(2,81)}=\right.$ $0.66, \mathrm{NS})$ and no nicotine by treatment interaction $\left(F_{(4,81)}=0.4\right.$, NS), indicating that MAOI treatments did not modify the psychostimulants effects of nicotine (Table 1). Moreover, there was a significant nicotine by day interaction $\left(F_{(10,405)}=27.4 ; p<\right.$ $0.001)$ but no treatment by day interaction $\left(F_{(10,405)}=0.9, \mathrm{NS}\right)$ and no nicotine by treatment by day interaction $\left(F_{(20,405)}=1.3\right.$, NS), indicating that MAOI treatments did not affect nicotineinduced locomotor activation or the development of nicotine sensitization.

\section{Effects of MAOI treatments on nicotine metabolism}

As indicated in Figure 2, MAOIs did not modify either clearance of nicotine or its accumulation after repeated nicotine injections (one injection every $12 \mathrm{~min}$ ). Overall, three-factor ANOVA indicated no group effect, a nicotine/cotinine difference $\left(F_{(1,10)}=34\right.$; $p<0.001)$, a time course effect $\left(F_{(7,70)}=36 ; p<0.001\right)$, but no group by nicotine/cotinine by time course interaction $\left(F_{(14,70)}=\right.$ $0.57, \mathrm{NS})$. Concerning the clearance observed after the first injection, nicotine decreased monotonically (Fig. 2, left), whereas cotinine increased (Fig. 2, right). After the fifth injection of nicotine, both groups were similar in terms of either nicotine (vehicle, $55.1 \pm 7.6 \mathrm{ng} / \mathrm{ml}$; TCP, $57.8 \pm 10.0 \mathrm{ng} / \mathrm{ml}$; PLZ, $70.7 \pm 12.6$ $\mathrm{ng} / \mathrm{ml} ; F_{(2,10)}=0.61, \mathrm{NS}$ ) (Fig. 2, left) or cotinine (vehicle, $39.5 \pm$ $11.2 \mathrm{ng} / \mathrm{ml} ; \mathrm{TCP}, 46.4 \pm 6.4 \mathrm{ng} / \mathrm{ml}$; PLZ, $47.4 \pm 4.0 \mathrm{ng} / \mathrm{ml}$; $F_{(2,10)}=0.34$, NS) (Fig. 2, right).

\section{Response to novelty}

Animals differed in their locomotor response to novelty (Fig. 3). On the basis of their mean locomotor responses over $120 \mathrm{~min}$, two groups, $\operatorname{LR}(846 \pm 54 ; n=69)$ and $\operatorname{HR}(1833 \pm 78 ; n=64)$, were designated as low and high responders $\left(t_{(133)}=10.6 ; p<\right.$ 0.001). Each LR and HR group was subdivided into three subgroups with equal activity scores (LR-vehicle, $929 \pm 75, n=23$; LR-TCP, $791 \pm 112, n=23$; LR-PLZ, $808 \pm 100, n=23 ; F_{(2,69)}=$ 0.6 , NS; HR-vehicle, $1793 \pm 112, n=21$, HR-TCP, $1847 \pm 175$, $n=21$; HR-PLZ, $1854 \pm 125, n=22 ; F_{(2,64)}=0.2$, NS) and were 
Table 1. Effects of vehicle, TCP-1.5, and PLZ-2 on behavioral sensitization to nicotine

\begin{tabular}{|c|c|c|c|c|c|c|c|}
\hline$\overline{\mathrm{MAOI}}(\mathrm{mg} / \mathrm{kg})$ & Nicotine $(\mathrm{mg} / \mathrm{kg})$ & Day 1 & Day 2 & Day 3 & Day 4 & Day 5 & Day 6 \\
\hline Vehicle & 0 & $300 \pm 27$ & $207 \pm 20$ & $193 \pm 18$ & $197 \pm 30$ & $206 \pm 18$ & $221 \pm 15$ \\
\hline TCP-1.5 & 0 & $206 \pm 25$ & $212 \pm 19$ & $170 \pm 22$ & $169 \pm 21$ & $180 \pm 17$ & $200 \pm 22$ \\
\hline PLZ-2 & 0 & $283 \pm 36$ & $238 \pm 26$ & $216 \pm 18$ & $199 \pm 22$ & $199 \pm 19$ & $216 \pm 22$ \\
\hline Vehicle & 0.2 & $130 \pm 17^{*}$ & $210 \pm 16$ & $203 \pm 22$ & $156 \pm 25$ & $266 \pm 26$ & $282 \pm 24$ \\
\hline ТCP-1.5 & 0.2 & $186 \pm 35$ & $205 \pm 31$ & $185 \pm 38$ & $191 \pm 23$ & $252 \pm 30$ & $218 \pm 23$ \\
\hline PLZ-2 & 0.2 & $191 \pm 26$ & $189 \pm 30$ & $244 \pm 27$ & $166 \pm 17$ & $233 \pm 32$ & $240 \pm 19$ \\
\hline Vehicle & 0.4 & $193 \pm 24^{*}$ & $310 \pm 17^{*}$ & $374 \pm 22^{*}$ & $393 \pm 23^{*}$ & $430 \pm 27^{*}$ & $421 \pm 24^{*}$ \\
\hline TCP-1.5 & 0.4 & $222 \pm 24$ & $286 \pm 23$ & $390 \pm 37^{*}$ & $418 \pm 27^{*}$ & $416 \pm 32^{*}$ & $458 \pm 40^{*}$ \\
\hline PLZ-2 & 0.4 & $239 \pm 22$ & $309 \pm 39$ & $409 \pm 34^{*}$ & $422 \pm 31^{*}$ & $441 \pm 31^{*}$ & $455 \pm 38^{*}$ \\
\hline
\end{tabular}

Once a day for $6 \mathrm{~d}$, rats received MAOI treatments followed $60 \mathrm{~min}$ later by an injection of nicotine $\left(0,0.2,0 \mathrm{or} 0.4 \mathrm{mg} / \mathrm{kg}\right.$, s.c.). Locomotor activity (mean photocell interruptions \pm SEM) was recorded for $20 \mathrm{~min}$. ${ }^{*} p<0.01$, significant difference when compared with the corresponding MAOI-vehicle group as revealed by Dunnett post hot test. $n=10$ for all MAOls.
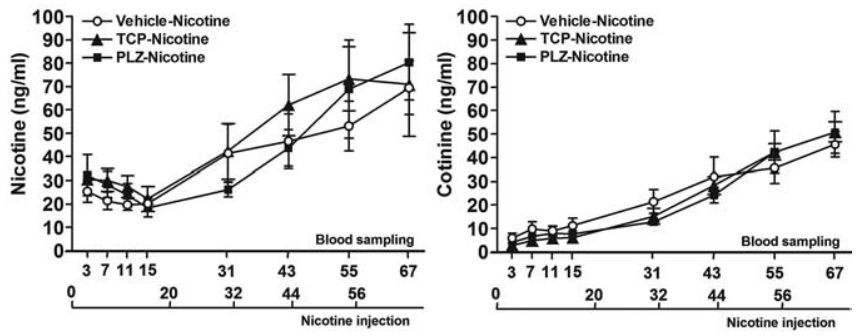

Figure 2. Plasma nicotine (left) and cotinine (right) (in nanograms per milliliter) after repeated intravenous injections of nicotine ( $30 \mu \mathrm{g} / \mathrm{kg}$ per injection, free base) to mimic nicotine SA. Rats were pretreated for $5 \mathrm{~d}$ with vehicle (circles; $n=4$ ), TCP (triangles; 1.5 $\mathrm{mg} \cdot \mathrm{kg}^{-1} \cdot \mathrm{d}^{-1} ; n=4$ ), or PLZ (squares; $2 \mathrm{mg} \cdot \mathrm{kg}^{-1} \cdot \mathrm{d}^{-1} ; n=5$ ). On the fifth day, rats received MAOI treatment, followed 60 min later by intravenous injections of nicotine. Error bars represent SEM.

assigned their respective pharmacological treatment (vehicle, TCP, and PLZ).

Experiment 1: effects of MAOI treatments on nicotine SA and food-maintained responding on a fixed-ratio schedule of reinforcement

Effects of MAOI treatments on nicotine SA (FR)

In the first experiment, animals were tested for acquisition of nicotine SA (Fig. 4). In our experimental conditions, all rats of all groups acquired nicotine SA. Considering the last three sessions of FR1 and FR5 (stabilized responding) for nicotine SA of rats treated with vehicle (reference animals for nicotine SA), the median and interquartile values for reinforced responses (RRs) and INJs were as follows: LR-RR-FR1 37 (22-76); HR-RR-FR1 36 (15-48); LR-RR-FR5 64 (31-87); HR-RR-FR5 71 (56-89); LRINJ-FR1 12 (8-18); HR-INJ-FR1 13 (12-18); LR-INJ-FR5 11 (514); and HR-INJ-FR5 8 (7-10). In vehicle-treated animals, although both groups demonstrated a preference for the active hole (for LR rats, $F_{(1,8)}=8.25, p<0.05$; for HR rats, $F_{(1,7)}=10.38, p<$ 0.01 ), only $\mathrm{HR}$ rats showed evidence for a progressive acquisition of nicotine SA, indicated by the increasing number of active versus inactive responses over the $23 \mathrm{~d}$ of testing (for LR rats, from $28.5 \pm 11.3$ on day 1 to $41.8 \pm 8.0$ on day $23 ; F_{(22,176)}=1.50$, NS; and for HR rats, from $24.3 \pm 5.7$ on day 1 to $61.4 \pm 12.7$ on day $\left.23 ; F_{(22,154)}=1.63, p<0.05\right)$. However, no significant difference between LR and HR vehicle-treated rats in the number of infusions obtained was detected at any time during this period (novelty by days, $F_{(22,330)}=0.99$, NS). Although PLZ and TCP treatments had no effect on responding in $\operatorname{LR}$ rats $\left(F_{(44,506)}=1.10\right.$, NS), they significantly enhanced the discrimination between the two holes in $\mathrm{HR}$ rats $\left(F_{(44,440)}=1.51 ; p<0.05\right)$.

Additional analysis revealed that, under this FR1 schedule, the

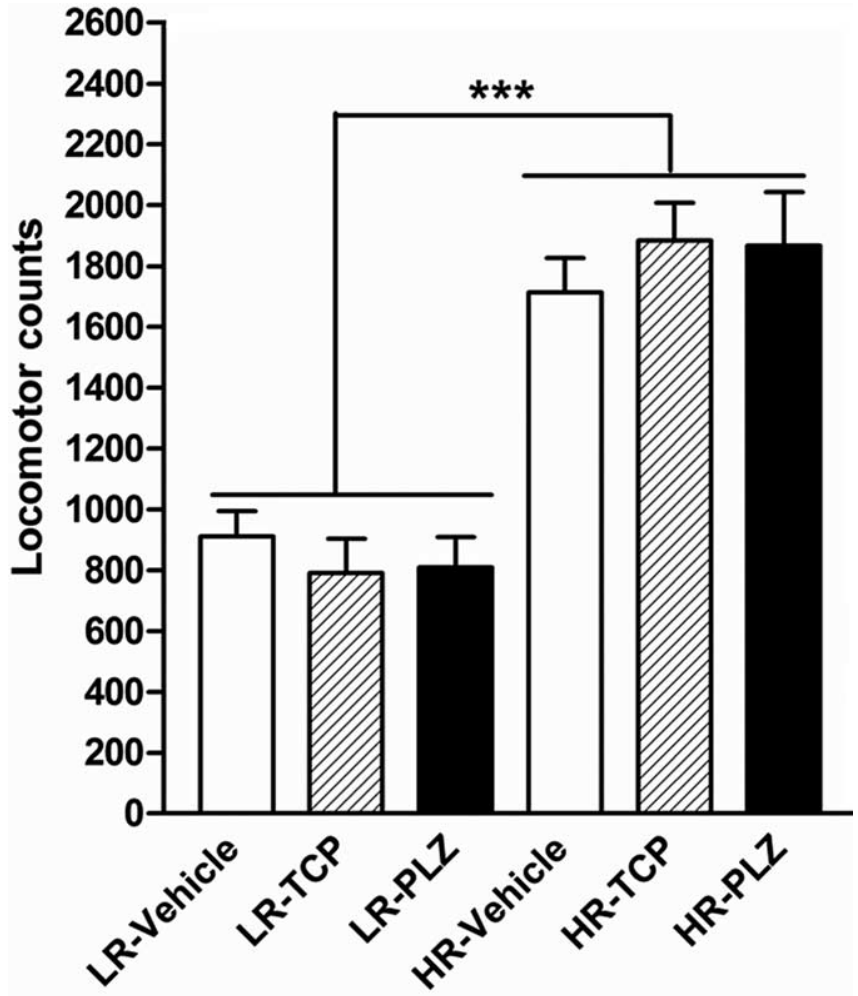

Figure 3. Evaluation of locomotor reactivity to novelty of the rats, which will be used in nicotine and food-maintained responding. Reactivity to novelty was assessed before any pharmacological treatment (vehicle, TCP, and PLZ), by measuring locomotor activity for $2 \mathrm{~h}$ in a novel environment (mean photocell interruptions \pm SEM). LR and HR rats corresponded, respectively, to the lower third and higher third of scores of the subject sample. The middle score subjects $(1 / 3)$ were discarded from the study. LR-Vehicle $(n=23), \operatorname{LR}-\mathrm{TCP}(n=23)$, and LR-PLZ $(n=23)$ and HR-Vehicle $(n=21)$, HR-TCP $(n=21)$, and HR-PLZ $(n=22) .{ }^{* *} p<0.001$, significant difference between groups as revealed by Newman-Keuls post hoc test.

primary reinforcing properties of nicotine appear to be unchanged by MAOI treatments in both LR and HR animals. Indeed, all groups of rats demonstrated the same level of responding (treatment effect, $F_{(2,44)}=0.45$, NS; novelty effect, $\left.F_{(1,44)}=0.80, \mathrm{NS}\right)$ and obtained the same number of nicotine infusions (treatment effect, $F_{(2,44)}=1.14$, NS; novelty effect, $\left.F_{(1,44)}=0.06, \mathrm{NS}\right)$.

However, under the FR5 schedule of reinforcement (Fig. 5a) (mean of the last $3 \mathrm{~d}$ of FR 5 representing stable nicotine SA), PLZ treatment increased responding for nicotine, whereas TCP had no effect $\left(F_{(2,44)}=7.90, p<0.001\right.$; PLZ vs vehicle, $p<0.01$; TCP vs vehicle, NS). Furthermore, PLZ-increased responding was selectively observed in $\mathrm{HR}$ rats $\left(F_{(2,44)}=6.10, p<0.01\right.$; HR-PLZ vs 


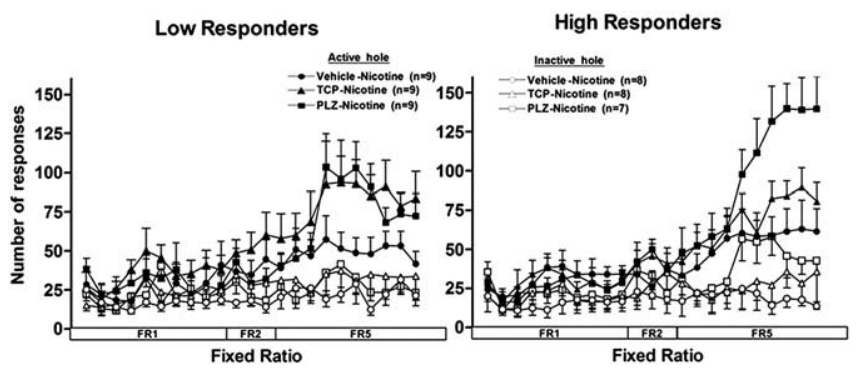

Figure 4. Effects of vehicle (circles), TCP (triangles; $1.5 \mathrm{mg} \cdot \mathrm{kg}^{-1} \cdot \mathrm{d}^{-1}$ ), and PLZ (squares; $2 \mathrm{mg} \cdot \mathrm{kg}^{-1} \cdot \mathrm{d}^{-1}$ ) pretreatment on acquisition of nicotine $S A$ in $L R$ and $H R$ animals on each of the $23 \mathrm{~d}$ of testing under fixed-ratio schedules of reinforcement (FR1, FR2, and FR5). Data are shown as mean responding \pm SEM on the active (filled symbols) and inactive (open symbols) holes.
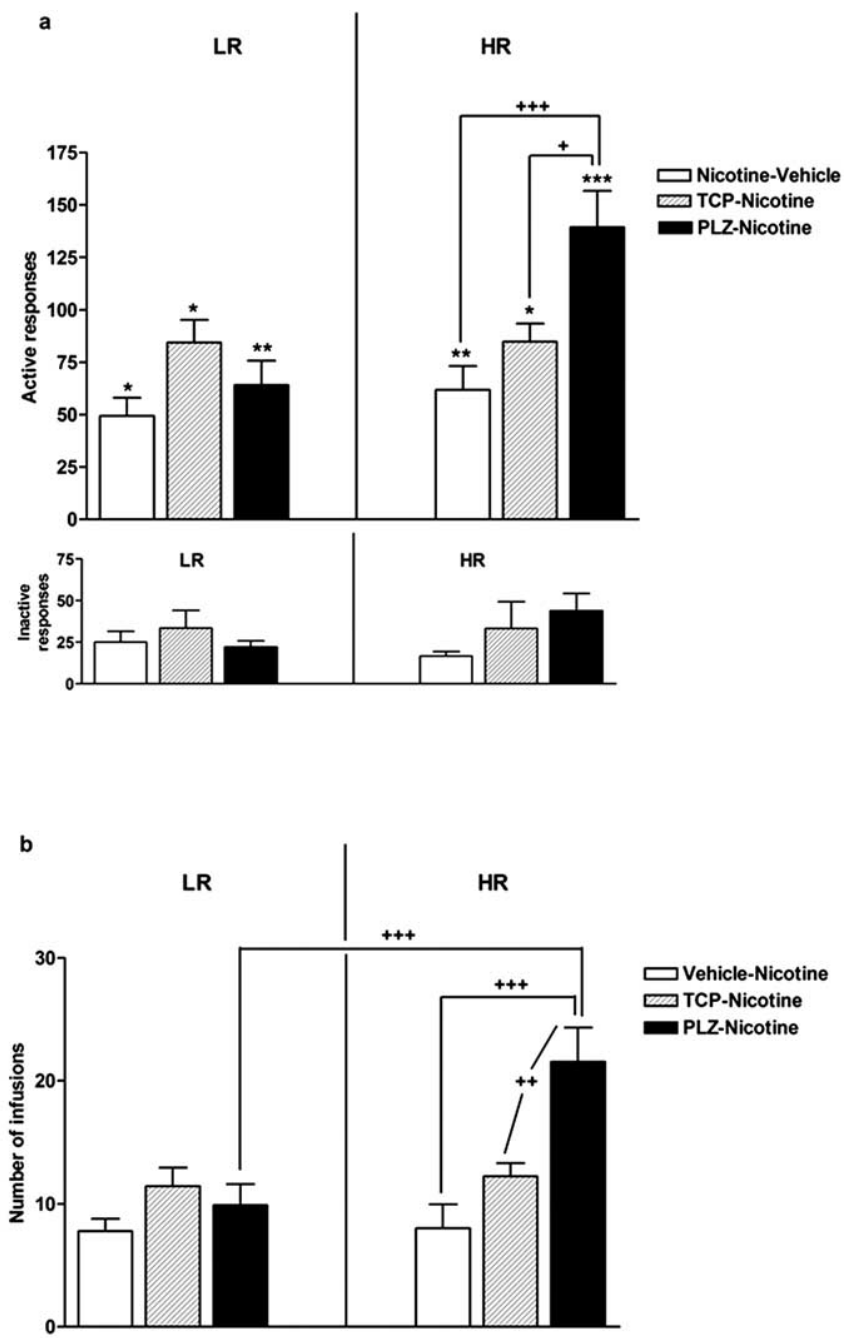

Figure 5. Effects of vehicle, TCP $\left(1.5 \mathrm{mg} \cdot \mathrm{kg}^{-1} \cdot \mathrm{d}^{-1}\right)$, and PLZ $\left(2 \mathrm{mg} \cdot \mathrm{kg}^{-1} \cdot \mathrm{d}^{-1}\right)$ pretreatment on stable nicotine self-administration under the FR5 schedule of reinforcement in $L R$ and HR animals. Mean scores \pm SEM during the last $3 \mathrm{~d}$ of the FR5. Each self-administration session lasted for 2 h. $\boldsymbol{a}$, Effects of MAOl pretreatment (white, hatched, and black bars show vehicle, TCP, and PLZ pretreatment, respectively) on the number of responses on the active hole (top) and on the inactive hole (bottom). ${ }^{*} p<0.05,{ }^{* *} p<0.01$, and ${ }^{* * *} p<0.001$, significant difference in response rates between the two holes in the same group of rats. ${ }^{+} p<0.05$ and ${ }^{++} p<0.001$, significant difference in responses rates between each subgroup as revealed by the Newman-Keuls post hoc test. $\boldsymbol{b}$, Effects of MAOI pretreatment on the number of nicotine infusions (30 $\mu \mathrm{g} / \mathrm{kg}$ per infusion). ${ }^{++} p<0.01$ and ${ }^{+++} p<0.001$, significant difference in nicotine intake between each subgroup as revealed by the Newman-Keuls post hoc test. Error bars represent SEM.
HR-Vehicle, $p<0.001$; HR-PLZ vs HR-TCP, $p<0.05)$, and this was specific to the active hole $\left(F_{(1,17)}=8.34, p<0.001\right)$, suggesting that this treatment had no general stimulatory effects on operant behavior. As a consequence, only animals treated with PLZ showed a higher rate of nicotine intake than vehicle-treated rats (Fig. 5b), whereas no difference was found between TCP and vehicle-treated animals $\left(F_{(2,44)}=10.89, p<0.001\right.$; PLZ vs vehicle, $p<0.01$; TCP vs vehicle, NS). Moreover, PLZ-increased nicotine intake was only observed in HR rats (treatment by novelty interaction, $F_{(2,44)}=8.26, p<0.001$; HR-PLZ vs LR-PLZ, $p<0.001$; HR-PLZ vs HR-vehicle, $p<0.001$; HR-PLZ vs HRTCP, $p<0.01)$, whereas no difference was found in the LR subgroup (NS).

Effects of MAOI treatments on food-maintained responding (FR) Furthermore, MAOI treatment-increased responding was specific for nicotine. Indeed, in the food-maintained responding experiment under fixed-ratio schedules (data not shown), all groups of rats demonstrated the same level of responding (treatment effect, $F_{(2,25)}=0.67$, NS; novelty effect, $\mathrm{F}_{1,25}=$ 0.02 , NS; days by hole by novelty by treatment interaction, $F_{(20,250)}=0.64$, NS).

Experiment 2: effects of MAOI treatments on nicotine SA and food maintained responding on a progressive-ratio schedule of reinforcement

Effects of MAOI treatments on nicotine $S A(P R)$

To further test the motivational significance of an interaction between MAOIs and nicotine, the behavior of the animals was studied in a more demanding task such as a PR schedule of reinforcement (Fig. 6a). Under PR schedules, the number of responses required to earn a single infusion increases with each infusion earned, and the measure of the final ratio attained (breaking point) allows one to assess the amount of effort an animal is willing to expend to obtain the reinforcer. In this task, all rats treated either by TCP or PLZ showed an increased level of motivation to obtain nicotine $\left(F_{(2,34)}=31,49, p<0.001\right.$; PLZ vs vehicle, $p<0.01$; TCP vs vehicle, $p<0.001)$. However, there was a significant effect of novelty $\left(\mathrm{F}_{(1,34)}=7.41 ; p<0.01\right)$ and a significant treatment by novelty interaction $\left(F_{(2,34)}=5.46 ; p<\right.$ $0.01)$, indicating different effects of treatments. Indeed, PLZ produced a higher breaking point in HR than in LR rats (LR-PLZ vs HR-PLZ, $p<0.001$ ), whereas TCP produced similar increases in both HR and LR rats.

Effects of MAOI treatments on food-maintained responding (PR) Concerning responding for food under a progressive ratio (Fig. $6 b)$, TCP and PLZ treatments had no effect on the breaking point attained. Indeed, the two-way ANOVA revealed no significant effect of treatment $\left(F_{(2,25)}=1.74\right.$, NS), novelty $\left(\mathrm{F}_{(1,25)}=0.04\right.$, NS), and no novelty by treatment interaction $\left(F_{(2,25)}=0.11, \mathrm{NS}\right)$ on operant responding for food.

\section{Experiment 3: effects of MAOI treatments on nicotine dose-response function}

Pretreatments with PLZ and TCP induced changes in the doseresponse curve (Fig. 7), as revealed by a significant treatment effect $\left(F_{(2,46)}=3.96, p<0.05\right.$; PLZ vs vehicle, $p<0.05$; TCP vs vehicle, $p<0.05)$. Moreover, there was a significant effect of dose $\left(F_{(6,276)}=11.42 ; p<0.001\right)$ and novelty $\left(F_{(1,46)}=10.80 ; p<\right.$ $0.01)$ on active responding, as well as significant dose by treatment and dose by novelty interactions $\left(F_{(12,276)}=6.63, p<0.001\right.$ and $F_{(6,276)}=2.21, p<0.05$, respectively). HR animals treated 


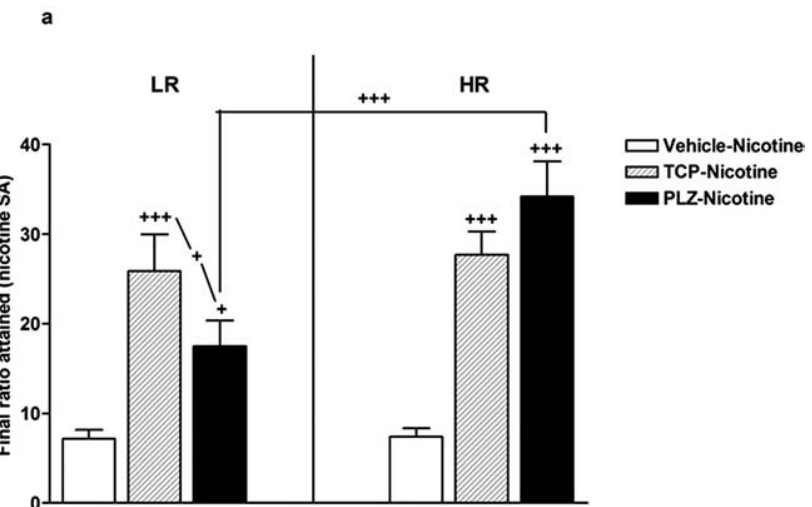

b

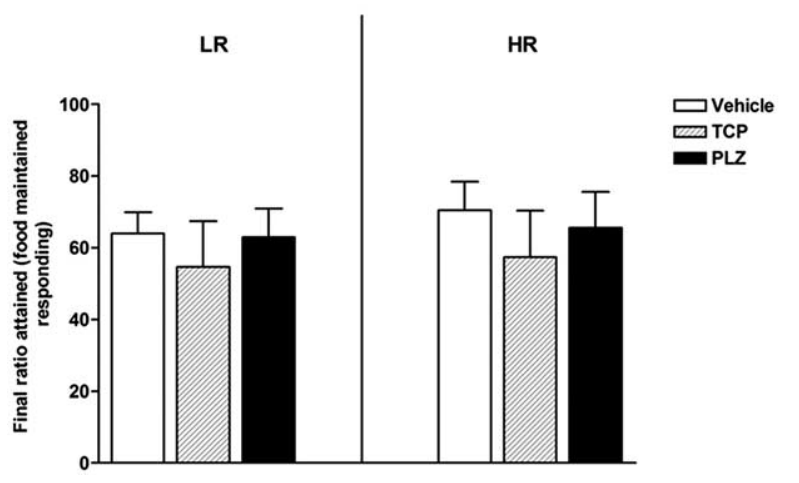

Figure 6. Effects of vehicle, TCP $\left(1.5 \mathrm{mg} \cdot \mathrm{kg}^{-1} \cdot \mathrm{d}^{-1}\right)$, and PLZ $\left(2 \mathrm{mg} \cdot \mathrm{kg}^{-1} \cdot \mathrm{d}^{-1}\right)$ pretreatment under the PR schedule of reinforcement on nicotine self-administration $(\boldsymbol{a})$ and food-maintained responding $(\boldsymbol{b})$ in LR and HR animals. Values represent the mean number of nose-poke responses ( $\boldsymbol{a})$ for nicotine self-administration and lever-press responses $(\boldsymbol{b})$ for foodmaintained responding, corresponding to the final ratio attained (breaking point) during the $5 \mathrm{~d}$ of the PR schedule of reinforcement. Vehicle, White bars; TCP, hatched bars; PLZ, black bars. ${ }^{+} p<0.05$ and ${ }^{+++} p<0.001$, significant difference between each subgroup as revealed by the Newman-Keuls post hoc test. Error bars represent SEM.

with vehicle demonstrated a more pronounced dose-response curve than LR rats, because only HR-vehicle animals showed evidence of a change in response rates over doses $\left(F_{(6,42)}=2.96\right.$; $p<0.05$ ) (Fig. 7a,c). In LR-vehicle group, whereas changing the unit dose had little effect on responding, the total intake increased from $\sim 12 \mu \mathrm{g} / \mathrm{kg}$ per session at $3 \mu \mathrm{g} / \mathrm{kg}$ unit dose to a maximum of $\sim 360 \mu \mathrm{g} / \mathrm{kg}$ per session at 45,60 , and $80 \mu \mathrm{g} / \mathrm{kg}$ unit doses (Fig. $7 b$ ). Conversely, a switch from $30 \mu \mathrm{g} / \mathrm{kg}$ per infusion (training dose) to $3 \mu \mathrm{g} / \mathrm{kg}$ per infusion in the HR group resulted in a significant decrease in response rates $(p<0.05)$ and in total intake $(p<0.001)$ (Fig. $7 d)$. However, at 60 and $80 \mu \mathrm{g} / \mathrm{kg}$ per infusion, response rates were not significantly modified when compared with $30 \mu \mathrm{g} / \mathrm{kg}$ per infusion, whereas the total intake increased to $\sim 500 \mu \mathrm{g} / \mathrm{kg}\left(F_{(6,42)}=22.68, p<0.001 ; 30\right.$ vs 60 and 30 vs $80, p<0.001$ ) (Fig. $7 c, d$ ).

Although it had no effect in the LR group, PLZ treatment shifted the ascending part of the dose-response curve slightly upward in HR animals. Indeed, these animals presented a higher rate of responding across doses $\left(F_{(12,132)}=5.13 ; p<0.001\right)$ (Fig. $7 a)$ and consumed little more nicotine $\left(F_{(12,132)}=2.43 ; p<0.01\right)$ (Fig. $7 b)$. Post hoc tests comparing each dose revealed that these animals presented a significantly higher rate of responding at the unit doses of 3, 7.5, and $30 \mu \mathrm{g} / \mathrm{kg}$ (HR-vehicle vs HR-PLZ, $p<$ 0.05 ), whereas total intake was significantly increased only at the two lowest doses ( $p<0.05$ at 3 and $7.5 \mu \mathrm{g} / \mathrm{kg}$ per infusion). In
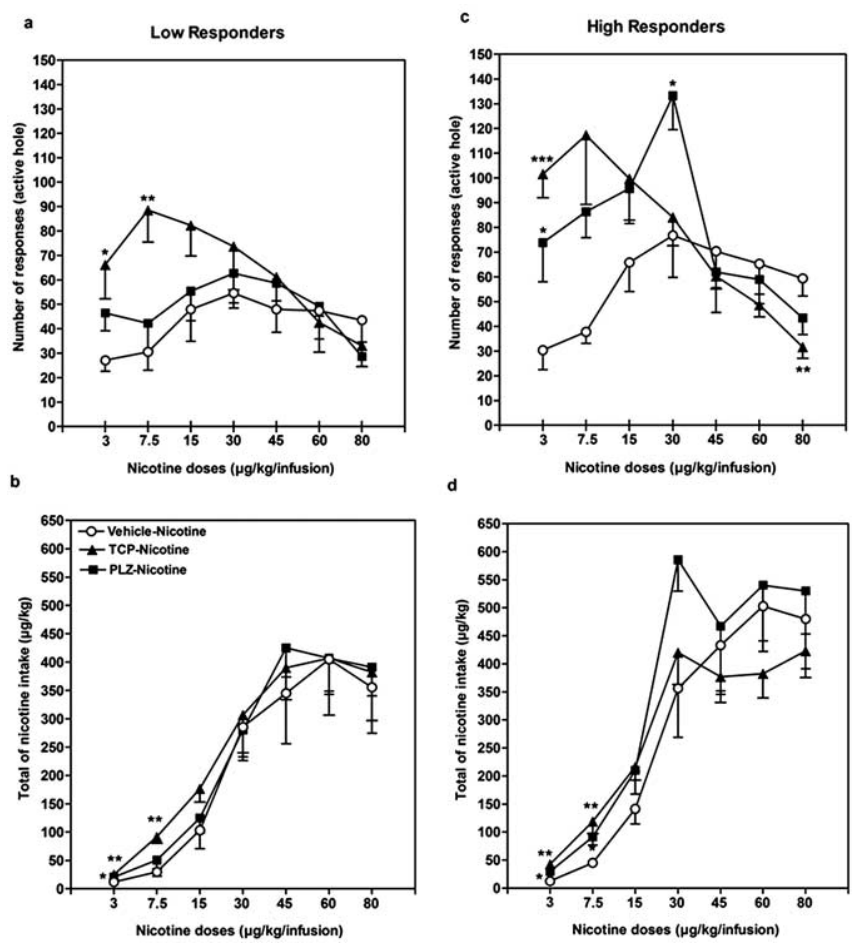

Figure 7. Effects of vehicle (circles), TCP (triangles; $1.5 \mathrm{mg} \cdot \mathrm{kg}^{-1} \cdot \mathrm{d}^{-1}$ ), and PLZ (squares; $\left.2 \mathrm{mg} \cdot \mathrm{kg}^{-1} \cdot \mathrm{d}^{-1}\right)$ on nicotine dose-response function in $\operatorname{LR}(\boldsymbol{a}, \boldsymbol{b})$ and HR $(\boldsymbol{c}, \boldsymbol{d})$ animals under the FR5 schedule of reinforcement. Each self-administration session lasted for 2 h. $\boldsymbol{a}, \boldsymbol{c}$, Effects of MAOI pretreatment on the number of responses on the active hole (mean \pm SEM) during the last day of each dose. ${ }^{*} p<0.05$ and ${ }^{* *} p<0.01$, significant difference in response rates between each group as revealed by the Newman-Keuls post hoc test. $\boldsymbol{b}, \boldsymbol{d}$, Effects of MAOI pretreatment on the total intake of nicotine (mean \pm SEM) earned at each unit dose. ${ }^{*} p<0.05$ and ${ }^{* *} p<0.01$, significant difference in nicotine intake between each group, as revealed by the Newman-Keuls post hoc test. The training dose was $30 \mu \mathrm{g} / \mathrm{kg}$ per infusion.

contract, TCP treatment horizontally shifted the dose-response curve to the left. Indeed, in all TCP-treated rats, the optimal number of responses for nicotine was moved to a lower unit dose of $7.5 \mu \mathrm{g} / \mathrm{kg}\left(F_{(2,24)}=8.19, p<0.01\right.$ and $F_{(2,22)}=5.30, p<0.01$ for LR and HR rats, respectively, vehicle vs TCP, $p<0.01$ ) (Fig. $7 a, c)$. Moreover, these animals developed self-administration at lower unit doses of 3 and $7.5 \mu \mathrm{g} / \mathrm{kg}\left(F_{(2,24)}=5.03\right.$ and $F_{(2,24)}=$ $7.05, p<0.01$ for LR rats; $F_{(2,22)}=8.38$ and $F_{(2,22)}=5.30, p<$ 0.01 for HR rats), whereas they reached a similar intake of nicotine at the highest doses (Fig. $7 b, d$ ).

\section{Discussion}

The present study demonstrates that chronic MAOI treatment enhances the reinforcing effects as well as the motivational properties of nicotine in rats. Indeed, animals pretreated with MAOIs self-administered a higher amount of nicotine (FR5) and worked more to obtain the drug when tested under the PR schedule of reinforcement. In addition, these effects were more prominent in rats selected for high responsiveness to novelty compared with those with low responsiveness.

The specificity of these treatments to increase nicotine selfadministration was further supported by the finding that these compounds did not increase either responding in the inactive hole or food-maintained responding. Furthermore, MAOI treatments did not modify the acute psychostimulant effects of nicotine and did not affect the development of behavioral sensitization to nicotine. Therefore, effects of MAOIs reflect heightened incentive motivational properties of nicotine rather than a gen- 
eral stimulatory effect on operant behavior. Moreover, as we observed in the present study, it has been shown previously that the MAOI doses used in our study did not result in any statistically significant difference in baseline locomotor activity (McManus et al., 1991).

TCP and PLZ are two irreversible MAOIs, inhibiting both MAO-A and MAO-B as soon as $1 \mathrm{~h}$ after administration (Baker et al., 1992; Griebel et al., 1998). The drug doses used in our study are consistent with previous investigations on the MAOinhibiting effects of the drugs. Indeed, chronic treatment with low doses of TCP $\left(1 \mathrm{mg} \cdot \mathrm{kg}^{-1} \cdot \mathrm{d}^{-1}\right)$ is known to block MAO-A and MAO-B activities by $>80 \%$ (McManus and Greenshaw, 1991; Todd and Baker, 1995). Increasing the dose of TCP to 3 and $15 \mathrm{mg} \cdot \mathrm{kg}^{-1} \cdot \mathrm{d}^{-1}$ did not induce additional inhibition of MAOs but rather induced collateral effects such as a direct releasing action on serotonin stores and increased locomotor activity (Green and Youdim, 1975; Ferrer and Artigas, 1994). Chronic treatments with low doses of PLZ $\left(2.5 \mathrm{mg} \cdot \mathrm{kg}^{-1} \cdot \mathrm{d}^{-1}\right)$ inhibit MAO-A and MAO-B by 83 and 58\%, respectively. Higher doses $\left(5 \mathrm{mg} \cdot \mathrm{kg}^{-1} \cdot \mathrm{d}^{-1}\right)$ lead to a greater inhibition of both types $(94$ and $88 \%$ for MAO-A and MAO-B, respectively) (Blier et al., 1986; Paslawski et al., 1996; Griebel et al., 1998) but are also known to act on other neurotransmitter systems such as by increasing the level of GABA in the entire brain (Popov and Matthies, 1969; Baker et al., 1991; Paslawski et al., 1996). Nevertheless, the dose-dependent effects of PLZ on MAO and GABA can be dissociated, and it has been shown that low doses of PLZ (2.5 $\left.\mathrm{mg} \cdot \mathrm{kg}^{-1} \cdot \mathrm{d}^{-1}\right)$, which inhibit MAO activity, do not affect GABA levels (Baker et al., 1991; Todd and Baker, 1995, Parent et al., 2000). Thus, the doses of TCP and PLZ used in our study (1.5 and 2.0 $\mathrm{mg} / \mathrm{kg}$, respectively) were specifically chosen to inhibit both MAO-A and MAO-B, without generating nonspecific effects.

As observed previously (Suto et al., 2001), the present results confirmed that, although HR and LR-vehicle-treated animals reached a similar number of infusions under simple FR schedules, HR rats performed slightly better than LR rats, because they increased responding at the active hole across acquisition sessions. However, in contrast to the results of Suto et al. (2001), no significant difference between LR and HR in response rates under the different FR and breaking point under PR schedule was detected in our study. An explanation for these differences could reside in the feeding conditions used in the present study, because rats were slightly food restricted to $20 \mathrm{~g} / \mathrm{d}$, which maintained moderate weight gain (Corrigall and Coen, 1989). Moreover, other studies have shown that nicotine reinforcement is sensitive to the availability of other reinforcers, like food (Lang et al., 1977; Singer et al., 1978; Dougherty et al., 1981); therefore, our mild food restriction regimen may have increased responding and then attenuated differences between LR and HR animals.

In addition, the fact that, in contrast to Suto et al. (2001), no difference between LR and HR rats was observed in our study under the PR may also be explained by a difference in the schedule used in the two studies. The PR sessions lasted only $2 \mathrm{~h}$ in the Suto study versus $10 \mathrm{~h}$ in the present one. Because, in the Suto study, LR rats acquired nicotine self-administration less readily than HR rats, the difference observed by these authors may actually be attributable to a lack of time rather than to a difference in motivation.

The results obtained with TCP showed that this treatment had no significant effect on nicotine intake during fixed-ratio schedules of reinforcement. Nevertheless, both HR and LR TCPtreated animals worked more than vehicle rats to obtain the drug when tested under a PR schedule, suggesting that this treatment selectively increased the incentive motivational effects of nicotine. In contrast to TCP, PLZ treatment differentially affected LR and HR animals. Under the FR5 schedule of reinforcement, PLZ treatment increased both active responding and nicotine intake in HR animals, whereas it had no effect in LR rats. Moreover, although all PLZ-treated animals increased their breaking point under the PR schedule, the final ratio attained was higher in HR rats. The specificity of these two MAOI treatments to increase the motivation for nicotine was further confirmed by the fact that these same treatments had no effect on responding for natural reinforcer such as food.

Our dose-response curves for nicotine SA are consistent with previous reports showing that within this dose-range and limited access schedule, responding maintained by nicotine was clearly dose dependent (Corrigall and Coen, 1989; Corrigall, 1992; Donny et al., 1995; Shoaib et al., 1997). Specially, our data confirmed those obtained by Donny et al. (1995). At the lowest dose, the average number of responses decreased compared with the training dose. Switching from 30 to $60 \mu \mathrm{g} / \mathrm{kg}$ per infusion produced a slight, but not significant, decrease in responding, but increased total intake. This effect was more prominent in HR than in LR-vehicle animals.

In the vehicle groups, changes in responding (number of responses) followed a dose-response function observed in literature in which response rates only rose between 7.5 and $30 \mu \mathrm{g} / \mathrm{kg} /$ injection. However, in the MAOI-treated animals, the doseresponse functions resemble those of heroin or cocaine, with an abrupt rise and a prominent descending component. Moreover, TCP and PLZ treatments had different effects on the doseresponse curve. TCP increased the sensitivity of nicotine in both LR and HR rats because the peak of the inverted U-shaped function was moved to $7.5 \mu \mathrm{g} / \mathrm{kg}$ per infusion (leftward shift). In contrast, PLZ induced a slight upward shift in the ascending limb of the curve in HR animals, indicating that this treatment increased the reinforcing efficacy of nicotine. Both MAOIs increased nicotine intake at the lowest dose ( 3 and $7.5 \mu \mathrm{g} / \mathrm{kg}$ per infusion), with no effect at the higher doses (60 and $80 \mu \mathrm{g} / \mathrm{kg}$ per infusion), suggesting that above this dose, nicotine might become aversive.

A possible explanation for these differences in MAOI effects could reside in the relative selectivity of inhibition of these MAOIs on the two MAO subtypes. Indeed, at the doses used in our study, chronic treatment with TCP results in a strong and equipotent inhibition of both MAO-A and MAO-B ( 88 and 93\%, respectively) (McManus et al., 1991; McManus and Greenshaw, 1991; Todd and Baker, 1995), whereas PLZ is slightly more potent in inhibiting MAO-A (MAO-A, 83\%; MAO-B, 58\%) (Baker et al., 1991), which preferentially deaminates serotonin and norepinephrine (Glover and Sandler, 1986; Fitton et al., 1992). However, because we only used nonselective MAOIs, definitive conclusions regarding the respective role of each subtype of MAO in the reinforcing and motivational properties of nicotine remain to be investigated. Moreover, it should be pointed out that the relative ratios of MAO-A and MAO-B are species specific, with MAO-B predominating in the human brain and MAO-A in the rat brain (Saura et al., 1992, 1996).

Another explanation for the differences in the action of TCP and PLZ resides in the fact that these treatments possess other pharmacological properties in addition to MAO inhibition. TCP is a mixed inhibitor of MAO-A and MAO-B that was described recently in in vitro experiments as being also an inhibitor of CYP2A6, the principle enzyme metabolizing nicotine to its inactive metabolite cotinine (Zhang and al., 2001). As such, it is possible that the increase in the breaking point observed in the pres- 
ence of TCP may be attributable to its inhibition of nicotine metabolism. However, our results indicate that there was no difference in the pharmacokinetics of nicotine and cotinine under TCP treatment. Thus, it is likely that the increase observed in the motivational properties of nicotine is attributable to the inhibitory activity on MAO of this compound rather than its inhibition of CYP2A6 cytochrome.

Together, the present results suggest that, in addition to nicotine, the MAO inhibitory activity of other compounds present in cigarette smoke may combine with nicotine and contribute, at least in part, to the reinforcing properties of tobacco. These findings have implications relevant for understanding the addiction liability of cigarette smoking and may suggest important new avenues for the development of more effective treatments for smoking cessation.

\section{References}

Baker GB, Wong JT, Yeung JM, Coutts RT (1991) Effects of the antidepressant phenelzine on brain levels of gamma-aminobutyric acid (GABA). J Affect Disord 21:207-211.

Baker GB, Coutts RT, McKenna KF, Sherry-McKenna RL (1992) Insights into the mechanisms of action of the MAO inhibitors phenelzine and tranylcypromine: a review. J Psychiatry Neurosci 17:206-214.

Berlin I, Anthenelli RM (2001) Monoamine oxidases and tobacco smoking. J Int Neuropsychopharmacol 4:33-42.

Berlin I, Said S, Spreux-Varoquaux O, Olivares R, Launay JM, Puech AJ (1995) Monoamine oxidase A and B activities in heavy smokers. Biol Psychiatry 38:756-761.

Blier P, De Montigny C, Azzaro AJ (1986) Modification of serotonergic and noradrenergic neurotransmissions by repeated administration of monoamine oxidase inhibitors: electrophysiological studies in the rat central nervous system. J Pharmacol Exp Ther 237:987-994.

Corrigall WA (1992) A rodent model of nicotine self-administration. In: Neuromethods, Vol 24, Animals models of drug addiction (Boulton AA, Baker GB, Wu PH, eds), pp 315-344. Totowa, NJ: Humana.

Corrigall WA, Coen KM (1989) Nicotine maintains robust self-administration in rats on a limited-access schedule. Psychopharmacology (Berl) 99:473-478.

Depoortere RY, Li DH, Lane JD, Emmett-Oglesby MW (1993) Parameters of self-administration of cocaine in rats under a progressive-ratio schedule. Pharmacol Biochem Behav 45:539-548.

Donny EC, Caggiula AR, Knopf S, Brown C (1995) Nicotine selfadministration in rats. Psychopharmacology (Berl) 122:390-394.

Dougherty J, Miller D, Todd G, Kostenbauder HB (1981) Reinforcing and other behavioral effects of nicotine. Neurosci Biobehav Rev 5:487-495.

Ferrer A, Artigas F (1994) Effects of single and chronic treatment with tranylcypromine on extracellular serotonin in rat brain. Eur J Pharmacol 263:227-234.

Fitton A, Faulds D, Goa KL (1992) Moclobemide: a review of its pharmacological properties and therapeutic use in depressive illness. Drugs 43:561-596.

Fowler JS, Volkow ND, Wang GJ, Pappas N, Logan J, MacGregor R, Alexoff D, Shea C, Schlyer D, Wolf AP, Warner D, Zezulkova I, Cilento R (1996a) Inhibition of monoamine oxidase B in the brains of smokers. Nature 379:733-736.

Fowler JS, Volkow ND, Wang GJ, Pappas N, Logan J, Shea C, Alexoff D, MacGregor RR, Schlyer DJ, Zezulkova I, Wolf AP (1996b) Brain monoamine oxidase A inhibition in cigarette smokers. Proc Natl Acad Sci USA 93:14065-14069.

Glover V, Sandler M (1986) Clinical chemistry of monoamine oxidase. Cell Biochem Funct 4:89-97.

Goldberg SR, Spealman RD, Goldberg DM (1981) Persistent behavior at high rates maintained by intravenous self-administration of nicotine. Science 214:573-575.
Green AR, Youdim MB (1975) Effects of monoamine oxidase inhibition by clorgyline, deprenil or tranylcypromine on 5-hydroxytryptamine concentrations in rat brain and hyperactivity following subsequent tryptophan administration. Br J Pharmacol 55:415-422.

Griebel G, Curet O, Perrault G, Sanger DJ (1998) Behavioral effects of phenelzine in an experimental model for screening anxiolytic and antipanic drugs: correlation with changes in monoamine-oxidase activity and monoamine levels. Neuropharmacology 37:927-935.

Jaffe JH, Kanzler M (1979) Smoking as an addictive disorder. NIDA Res Monogr 23:4-23.

Lang WJ, Latiff AA, McQueen A, Singer G (1977) Self-administration of nicotine with and without a food delivery schedule. Pharmacol Biochem Behav 7:65-70.

McManus DJ, Greenshaw AJ (1991) Differential effects of antidepressants on GABAB and beta-adrenergic receptors in rat cerebral cortex. Biochem Pharmacol 42:1525-1528.

McManus DJ, Mousseau DD, Paetsch PR, Wishart TB, Greenshaw AJ (1991) Beta-adrenoceptors and antidepressants: possible 2-phenylethylamine mediation of chronic phenelzine effects. Biol Psychiatry 30:1122-1130.

Parent MB, Habib MK, Baker GB (2000) Time-dependent changes in brain monoamine oxidase activity and in brain levels of monoamines and amino acids following acute administration of the antidepressant/antipanic drug phenelzine. Biochem Pharmacol 59:1253-1263.

Paslawski T, Treit D, Baker GB, George M, Coutts RT (1996) The antidepressant drug phenelzine produces antianxiety effects in the plus-maze and increases in rat brain GABA. Psychopharmacology (Berl) 127:19-24.

Piazza PV, Deminiere JM, Le Moal M, Simon H (1989) Factors that predict individual vulnerability to amphetamine self-administration. Science 245:1511-1513.

Poindexter EH, Carpenter RD (1962) The isolation of harmane and norharmane from tobacco and cigarette smoke. Phytochemistry 1:215-221.

Pontieri FE, Tanda G, Orzi F, Di Chiara G (1996) Effects of nicotine on the nucleus accumbens and similarity to those of addictive drugs. Nature 382:255-257.

Popov N, Matthies H (1969) Some effects of monoamine oxidase inhibitors on the metabolism of gamma-aminobutyric acid in rat brain. J Neurochem 16:899-907.

Rommelspacher H, Meier-Henco M, Smolka M, Kloft C (2002) The levels of norharman are high enough after smoking to affect monoamine oxidase B in platelets. Eur J Pharmacol 441:115-125.

Rose JE, Corrigall WA (1997) Nicotine self-administration in animals and humans: similarities and differences. Psychopharmacology (Berl) 130:28-40.

Saura J, Kettler R, Da Prada M, Richards JG (1992) Quantitative enzyme radioautography whith $3 \mathrm{H}-\mathrm{Ro} 41-1049$ and $3 \mathrm{H}-\mathrm{Ro}$ 19-6327 in vitro: localization and abundance of MAO-A and MAO-B in rat CNS, peripheral organs, and human brain. J Neurosci 12:1977-1999.

Saura J, Nadal E, van den Berg B, Vila M, Bombi JA, Mahy N (1996) Localization of monoamine oxidases in human peripheral tissues. Life Sci 59:1341-1349.

Shoaib M, Schindler CW, Goldberg SR (1997) Nicotine self-administration in rats: strain and nicotine pre-exposure effects on acquisition. Psychopharmacology (Berl) 129:35-43.

Singer G, Simpson F, Lang WJ (1978) Schedule induced self-injection of nicotine with recovered body weight. Pharmacol Biochem Behav 9:387-389.

Stolerman IP, Jarvis MJ (1995) The scientific case that nicotine is addictive. Psychopharmacology (Berl) 117:2-10.

Suto N, Austin JD, Vezina P (2001) Locomotor response to novelty predicts a rat's propensity to self-administer nicotine. Psychopharmacology (Berl) 158:175-180.

Todd KG, Baker GB (1995) GABA-elevating effects of the antidepressant/ antipanic drug phenelzine in brain: effects of pretreatment with tranylcypromine, (-)-deprenyl and clorgyline. J Affect Disord 35:125-129.

Zhang W, Kilicarslan T, Tyndale RF, Sellers EM (2001) Evaluation of methoxsalen, tranylcypromine, and tryptamine as specific and selective CYP2A6 inhibitors in vitro. Drug Metab Dispos 29:897-902. 